\title{
DESAFIOS PARA VALORAÇÃO DAS PATENTES NO BRASIL: UM ESTUDO DE CASO SOBRE OS PRODUTOS/PROCESSOS PARA REMEDIAÇÃO AMBIENTAL
}

\author{
CHALLENGES FOR PATENT VALUATION IN BRAZIL: A CASE STUDY ON \\ PRODUCTS / PROCESSES FOR ENVIRONMENTAL REMEDIATION
}

\begin{abstract}
Antonio Fredson Araujo de Sá Novaes Mestrando na Universidade Federal do Vale do São Francisco - PROFNIT/Univasf, Brasil
\end{abstract} Diretor do Departamento de Sistemas de Informações - Univasf, Brasil antonio.fredson@univasf.edu.br

\author{
Vivianni Marques Leite dos Santos \\ Docente na Universidade Federal do Vale do São Francisco - Univasf, Brasil \\ Coordenadora e Docente no Mestrado Profissional em Propriedade Intelectual e Transferência de Tecnologia \\ para a Inovação (PROFNIT) \\ Docente no Doutorado em Agroecologia e Desenvolvimento Territorial (PPGADT) \\ vivianni.santos@univasf.edu.br
}

\begin{abstract}
Resumo: No contexto das mudanças negativas oriundas dos impactos ambientais e do incentivo à inovação como alternativa para minimizar os referidos impactos, este artigo tem como objetivo analisar duas questões: Como está a produção patentária na área de meio ambiente, especificamente na temática da remediação? E ainda, se as referidas patentes estão chegando ao mercado e/ou se estão sendo valoradas? Para isto, foram realizadas buscas nas bases de patentes do INPI e disponíveis no Orbit, além de pesquisa na literatura e aplicação de questionários. Verifica-se que são poucas as patentes de remediação ambiental no Brasil e que ainda existem muitas dificuldades para a valoração de patentes em geral, embora identificados 7 métodos. Ademais, os principais desafios estão na escassez de publicação na temática com detalhamentos dos passos empregados em casos práticos; métodos ainda necessitam adequações para valoração de novas tecnologias; falta de capacitação; e, especificamente, para as patentes na área de meio ambiente, incluindo tecnologias para remediação, a falta de parâmetros que considerem os ganhos e vantagens estratégicas a partir do cumprimento de responsabilidades ambientais.
\end{abstract}

Palavras-chave: Inovação. Patente. Impacto ambiental. Valoração.

\begin{abstract}
In the context of the negative changes arising from environmental impacts and the incentive to innovation as an alternative to minimize these impacts, this article aims to analyze two questions: How is patent production in the environmental area, specifically in the theme of remediation? And also, if are these patents reaching the market and/or are these being valued? For this, searches were carried out on the INPI patent bases and available on Orbit, in addition to searching the literature and applying questionnaires. It was verified that there are few patents for environmental remediation in Brazil and still many difficulties for the valuation of patents in general, although 7 methods have been identified. Furthermore, the main challenges are scarcity of publication on the area with details about steps used in practical cases; methods still require adaptations for the valorization of new technologies; lack of training; and specifically for environmentally related patents, including technologies for remediation, the lack of parameters that consider the gains and strategic advantages from the fulfilment of environmental responsibilities.
\end{abstract}

Keywords: Innovation. Patent. Environmental impact. Valuation.

Cite como

American Psychological Association (APA)

Novaes, A. F. A. S., \& Santos, V. M. L. (2021, jan./jun.). Desafios para valoração das patentes no Brasil: um estudo de caso sobre os produtos/processos para remediação ambiental. Revista Inovação, Projetos e Tecnologias - IPTEC, São Paulo, 9(1), 17-31. https://doi.org/10.5585/iptec.v9i1.18207. 


\section{Introdução}

Muito tem se discutido sobre a importância das inovações, assim como a necessidade da proteção realizada com o registro de patente ao longo do tempo, dado que uma patente somente resulta em inovação se a mesma chegar ao mercado. Segundo Romer (1987), a incorporação de ideias já constituía o principal motor de crescimento econômico na década de 1980. Por outro lado, as questões ambientais também têm sido discutidas e verificada a necessidade de desenvolvimento tecnológico na área, sua proteção e a sua absorção ou utilização pelo mercado, gerando de fato inovação (Romeiro \& Salles, 2001, p. 85).

A pergunta é: E quanto às inovações para redução da poluição e acidentes ambientais? Oliveira e Ewald (2011) registraram que, devido ao crescente nível de degradação ambiental, as empresas estão investindo em tecnologias amigáveis ao meio ambiente, surgindo novas ferramentas, instrumentos e sistemas. Entretanto, de acordo com os autores, os avanços tecnológicos não têm surtido efeitos visíveis para os cidadãos, na mesma proporção do número de patentes.

Aguiar e Gabriel (2014) defendem que iniciativas para remediação do solo, da água e do ar são elementos-chave para a gestão ambiental de empresas e governos, diante da problemática envolvendo a sociedade e as questões ambientais e da necessidade de produção amigável ao ambiente. Os autores concluíram pela eficácia e eficiência de um sistema de remediação ambiental por injeção de solução de melaço na água subterrânea para redução do cromo hexavalente com resultado positivo em $100 \%$ dos poços monitorados.

Com base na experiência de um dos autores deste artigo, durante gestão do Núcleo de Inovação Tecnológica (NIT) da sua Instituição, a dificuldade na valoração das patentes tem sido gargalo para a inserção de novas tecnologias no mercado. Analisa que uma das causas pode estar na pequena produção científica disponível com essa abordagem. São apenas 22 na CAPES (https://www.periodicos.capes.gov.br, recuperado em maio, 2020), considerando os periódicos revisados por pares e com tópico patent valuation, e 1 na SCIELO (https://scielo.org, recuperado em junho, 2020), usando as palavras chaves valuation e patent.

Com relação aos programas como aquele de Patentes Verdes, que agilizam o processo de análise de patentes, Resolução INPI no 239/2019 (2019), entre outros estímulos à inovação para promoção do meio ambiente, a pergunta é: As patentes verdes ou aquelas associadas ao desenvolvimento ambiental estão sendo valoradas? Ou ainda: Estão chegando ao mercado?

A Associação Nacional de Análise de Avaliação Certificada (National Association of Certified Valuation Analysis) nos Estados Unidos, especificam métodos de valoração para 
tecnologias (Hong, Seo, Kim, \& Kang, 2009) e de acordo com Hitchner e Mard (2006), as abordagens de renda, de mercado e de custo são os 3 tipos comumente utilizados na indústria.

Porém, a questão ainda prevalece em muitos NITs: Como obter o valor adequado para uma nova tecnologia patenteada? Nesse sentido, Thorn, Hunt, Mitchell, Probert e Phaal (2011) argumentaram sobre a complexidade oriunda da elevada incerteza e dificuldades na maioria das valorações de novas tecnologias, com aumento significativo quando relacionadas as tecnologias em estágios iniciais ou em baixos níveis de maturidade. Assim, é difícil mensurar a justa remuneração por uma patente, a começar pela escolha do método de valoração, dado o pouco conhecimento disponível e a natureza deste tipo de propriedade intelectual (PI).

Ademais, assim como concluído por Souza (2009), como limitação do seu estudo, quanto à dificuldade na obtenção de informações sobre as técnicas de valoração usadas pelas petrolíferas, também não estão acessíveis os métodos utilizados pelos diversos NITs no Brasil. Para Adriano e Antunes (2017), apesar dos avanços, existem poucas evidências práticas relativas aos indicadores para determinação de preços, custos e quantidades de vendas dos produtos protegidos por patentes.

Para os ativos intangíveis, em geral, os métodos utilizados pela contabilidade não realizam adequadamente sua valoração (Damodaran, 2006), além de que há dificuldades para propor um método para valorar aqueles ativos (Andriessen, 2004). Algumas propostas e/ou estudos de valoração de patentes são apresentadas em artigos (Souza, 2009; Amaral, Iquiapaza, Correia, Amaral, \& Vieira, 2014; Adriano \& Antunes, 2017; Reitzig (2003); Sapsalis \& Van Pottelsberghe De La Potterie (2007) e Thorn et al., 2011), porém suas aplicações e/ou detalhamentos incompletos ainda geram incertezas e procedimentos não padronizados.

Por outro lado, Souza (2009) utilizou métodos distintos para uma mesma patente, um robô para inspeção e desobstrução de dutos, chegando a valores discrepantes (diferença maior que $56 \%$ ). Obteve o valor de US\$100.800,00 através de um método empírico utilizado pelo mercado, baseado na valoração pela parcela de royalties; o valor de US $\$ 177.749,00$, baseado na Teoria de Opções Reais e o valor de US\$126.129,51, que foi calculado a partir de método proposto na sua dissertação. De fato, artigos como este contribuem para elucidação de dúvidas.

Devido aos desafios para valorização das patentes, apesar dos esforços depreendidos até esta data e assim como destacado por Ernst, Legler, \& Lichtenthaler, em 2010, ainda há necessidade de pesquisas na área. Ademais, de acordo com Ernst et al. (2010), a despeito dos avanços teóricos e empíricos, a valoração de patentes continua constituindo um gargalo para a transferência de novas tecnologias para o mercado, atribuindo isso à difusão de modelos 
teóricos e concluindo pela necessidade de incentivo aos estudos empíricos e, segundo Banerjee et al. (2017), obter retorno dos gestores dos NITs quanto ao uso dos métodos.

Quintal e Terra (2014) realizaram um estudo com 5 Instituições de Pesquisa com o objetivo de identificação e comparação acerca dos métodos para valoração de patentes. Concluíram que os NITs têm organogramas distintos; há unânime preocupação com a capacitação das equipes e destaca que as patentes não vêm sendo valoradas, bem como seus bancos de patentes, em geral, não contém tecnologias licenciadas ou geradoras de receitas.

No caso das tecnologias amigáveis ao meio ambiente, temática principal deste estudo, a escassez de pesquisas é ainda maior e, devido aos crescentes impactos ambientais negativos, estima-se que há necessidade de maior incentivo. Hung e Tseng (2010) ressaltaram que a valoração de tecnologias ambientais deve considerar além das questões econômicas, os seus efeitos ou ganhos para o meio ambiente a partir do cumprimento de responsabilidades sociais e geração de vantagens competitivas, por exemplo. Assim, a escassez de pesquisas aplicadas, com descrição dos cálculos e parâmetros, limita a escolha do método para valoração, notadamente, quando ligadas à remediação ambiental, julgada nesse estudo, uma opção promissora contra impactos ambientais negativos.

Nesse contexto, visando atender as duas questões: Como está a produção patentária na área de meio ambiente, especificamente na temática da remediação ambiental? E ainda, se as referidas patentes estão sendo valoradas e se estão chegando ao mercado? O objetivo é identificar patentes relacionadas à temática de Remediação Ambiental, bem como quais métodos vêm sendo utilizados para sua valoração e se há indicação de fatores adicionais a serem considerados, bem como se aquelas tecnologias têm sido aplicadas ou inseridas no mercado.

\section{Metodologia}

Esta pesquisa tem natureza aplicada (Gil, 2017), uma vez que gera conhecimentos para buscar solucionar a problemática da valoração de patentes nas Instituições Científicas e Tecnológicas (ICTs), ao passo que quanto aos objetivos (Gil, 2017), trata-se de uma pesquisa exploratória, descritiva e explicativa, devido ser realizada com base em pesquisa a partir da literatura e levantamento de dados em bases de patentes, seguida pela descrição do diagnóstico acerca da produção patentária envolvendo remediação ambiental, além da discussão acerca das causas para os desafios identificados para a valoração de tecnologias patenteadas.

Para esta pesquisa, foi realizada consulta em bases de periódicos, Google Acadêmico e Períodos CAPES e em bases de patentes, incluindo a base nacional a partir do site do escritório 
brasileiro de patentes, o Instituto Nacional de Propriedade Industrial (INPI) e também utilizando o software de busca e tratamento de patentes, o Questel Orbit. As buscas foram realizadas por famílias de patentes. No Orbit, optou-se pela busca avançada nos títulos ou resumos, com as palavras-chave environmental AND remediation, incluindo suas versões em português. Ao passo que no sítio do INPI, foram utilizadas as palavras "remediação AND ambient*" na busca avançada a partir dos resumos (em 04/06/2020). Devido ao foco na valoração para transferência das tecnologias (TTs) associadas à remediação ambiental, realizou-se também a busca na base de TT, com as palavras-chave contidas nos termos dos certificados.

Para as patentes nacionais, com titulares tipo empresas ou CNPJ, foram acessados os sites das mesmas, visando obter possíveis informações sobre divulgação das patentes, suas aplicações, orçamentos, valoração e transferências das tecnologias, etc., além de realizado contato eletrônico (e-mail) quando necessário, no sentido de complementar informações relacionadas às patentes já concedidas, ou seja, deferidas e emitidas as cartas-patente.

Para complementar informações, foi enviado, por meio eletrônico, um questionário para gestores de NITs das Instituições Cientificas e Tecnológicas (ICTs) do Brasil. Utilizou-se o Google forms, contendo dados de identificação da ICT e os quesitos: 1) Qual a quantidade de pedidos de patentes já realizados pela instituição?; 2) Qual a quantidade de pedidos de patentes já licenciadas pela instituição?; 3) Qual a quantidade de patentes já valoradas na instituição?; 4) Quais as metodologias de cálculo utilizadas na valoração de patentes na instituição?; 5) Uma ou algumas destas metodologias foi ou foram criadas pela própria Instituição?; 6) Quais as dificuldades encontradas na valoração de patentes na instituição?; 7) Entre as patentes valoradas na instituição, existe alguma relacionada à remediação ambiental? Qual(is)? 8) Campo para quaisquer informações adicionais que julgue pertinentes.

Para aplicação do questionário foram enviados convites para representantes das ICTs e membros do Fórum Nacional dos Gestores de Inovação e Transferência de Tecnologia (FORTEC), por e-mail e whatsapp, em maio de 2020, pedindo apoio àqueles que estão atuando como gestores de NITs, no sentido de preencher o formulário no prazo de até 30 dias. Assim, a amostra é do tipo conveniência, devido à dificuldade e voluntariedade da participação, focando na descrição e exatidão dos dados e não na quantidade, tal como o estudo de Quintal e Terra (2014), que baseou-se em 5 ICTs. 


\section{Resultados obtidos e análise}

Das 1089 patentes obtidas a partir da base de dados do Orbit, em junho de 2020, usando as palavras-chave environmental e remediation, nos títulos e resumos, 795 estão ativas (372 concedidas e 423 pendentes) e outras 294 estão em situação de revogadas, expiradas ou caducadas (Figura 1). Importante observar que a maioria, 664 registros (617 ativos), obteve solicitação de proteção somente após o ano de 2015.

Figura 1 - Percentual de família de patentes na área de remediação ambiental por situação ou status

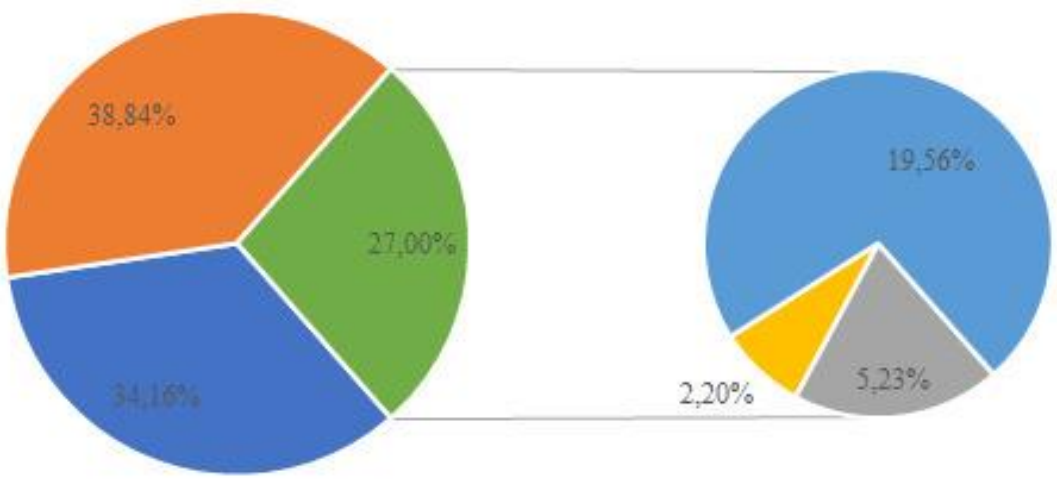

- Concedida (372) - Pendente (423) =Inativa (294) | Revogada (57) | Expirada (24) - Caducada (213)

Fonte: Adaptada a partir do Orbit (2020)

Apesar do aparente número elevado, considerando que no Orbit estão disponíveis 20.130.152 patentes ativas, apenas $0,004 \%$ das patentes ativas constituem desenvolvimentos na área de Remediação Ambiental. Além disso, de todas as patentes nesta área, apenas 2 estão como licenciadas (licensed).

Analisando o cenário mundial, verifica-se que a China lidera entre os TOP 10 países com maiores quantitativos de famílias de patentes ativas na área de remediação ambiental (Figura 2) (678), seguida, de longe, pelos Estados Unidos (81 famílias de patentes ativas). O Brasil desponta em $4^{\circ}$ lugar, embora com apenas 18 famílias patentes ativas na área, tal como a Índia e o número de depósitos no escritório da WIPO (World Intellectual Property Organization) ou OMPI (Organização Mundial da Propriedade Intelectual). 
Figura 2 - Famílias de patentes por escritório/país de publicação

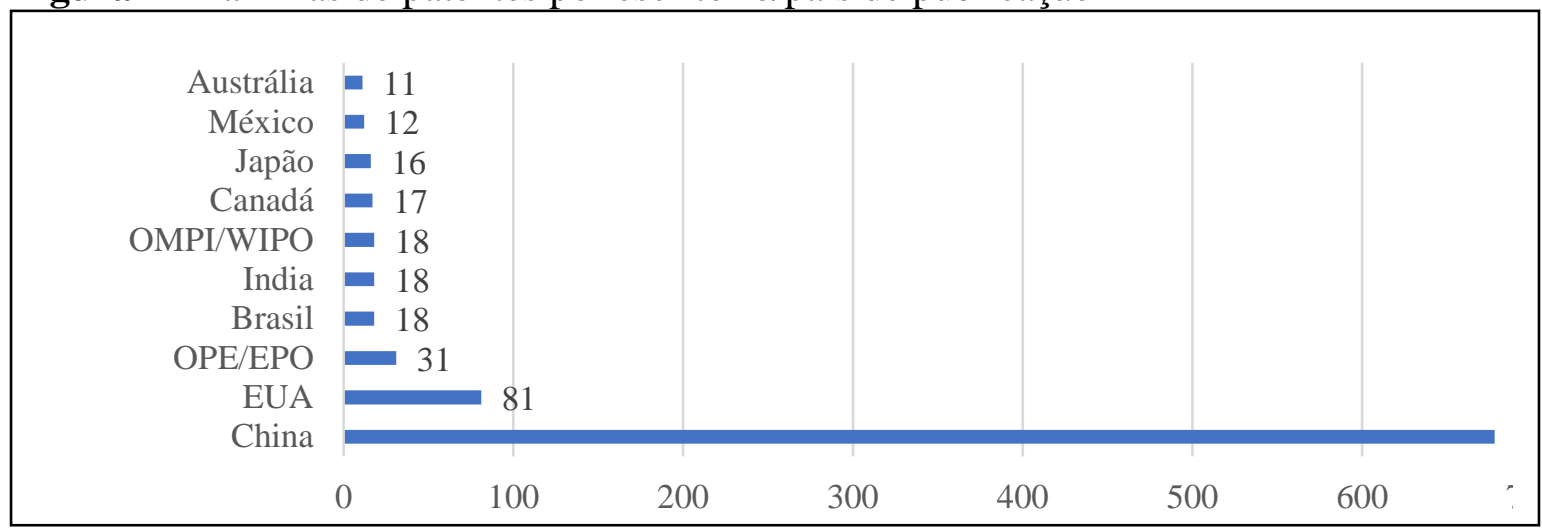

Fonte: Adaptada a partir do Orbit (2020)

Refazendo a busca no Orbit, utilizando as palavras-chave "remediação AND ambient*" no resumo, foram localizadas 43 famílias de patentes. Destas, 31 de origem brasileira, porém uma foi publicada também nos Estados Unidos, por meio do Tratado de Cooperação em matéria de Patentes ou Patent Cooperation Treaty (PCT). Entre as patentes nacionais, 4 foram concedidas, 14 estão pendentes, 9 revogadas e 4 caducadas. Portanto, apenas 18 ativas, destacando que nenhuma delas foi publicada fora do Brasil.

Do total de patentes publicadas no site do INPI (http://www.inpi.gov.br, recuperado em junho, 2020), o número é maior (45), sendo 32 de origem nacional ou com titulares residentes e 13 de origem estrangeira (titulares não residentes). Com foco nas patentes de residentes encontradas na base de patentes do INPI, foram identificadas as seguintes situações:

a) Quanto ao depositante/titular, considerando as patentes depositadas por residentes, 27 (84\%) são de pessoas jurídicas e 5 (16\%) são de pessoas físicas.

b) Quanto à quantidade por estado da Federação (Figura 3), São Paulo é o estado brasileiro com mais patentes na área de Remediação Ambiental depositadas no INPI, com 6 patentes no total, seguido por Minas e Paraná, com 5 e Rio de Janeiro, com 4, de forma que as Regiões com maior número de patentes na área são a Sudeste e a Sul. 
Figura 3 - Quantidade de patentes depositadas por residentes no INPI e PIB em milhões de reais por unidade de federação

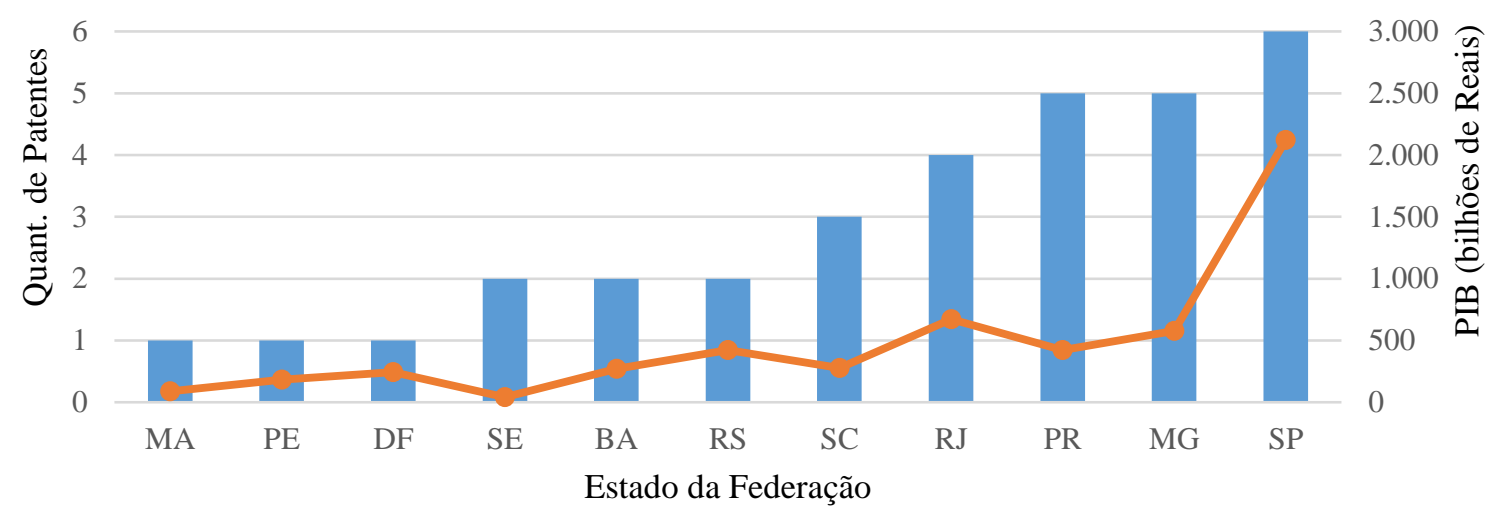

Quantidade de patentes —PIB 2017 em bilhôes de reais

Fonte: Elaborada a partir de dados do INPI (2020) e do IBGE (2020).

Em análise mais detalhada acerca da quantidade de patentes por estados, verifica-se que o produto interno bruto (PIB) de São Paulo, no ano de 2017, conforme dado mais atualizado no site do IBGE (https://www.ibge.gov.br/explica/pib.php, recuperado em novembro, 2020), é bastante elevado quando comparado com os demais estados, o que indica correlação positiva com o quantitativo de patentes, embora esta diferença não reflita tão fortemente sobre os depositantes residentes nos estados do Paraná e Minas Gerais, principalmente quando comparado com o PIB do Rio de Janeiro. Em estudos futuros, recomenda-se uma análise mais aprofundada sobre a referida correlação.

c) As patentes de residentes (depositadas no INPI), no período de 2002 a 2018 (Figura 4), alcançaram o máximo de depósitos em 2013, com 6 patentes. Destaca-se que as patentes anteriores ao século XXI foram depositadas no Brasil por não residentes e constituíram as 3 primeiras patentes de Remediação Ambiental ainda na década de 90 (uma em 1993 e duas em 1997).

Figura 4 - Quantidade de patentes depositadas por residentes, por ano, no INPI

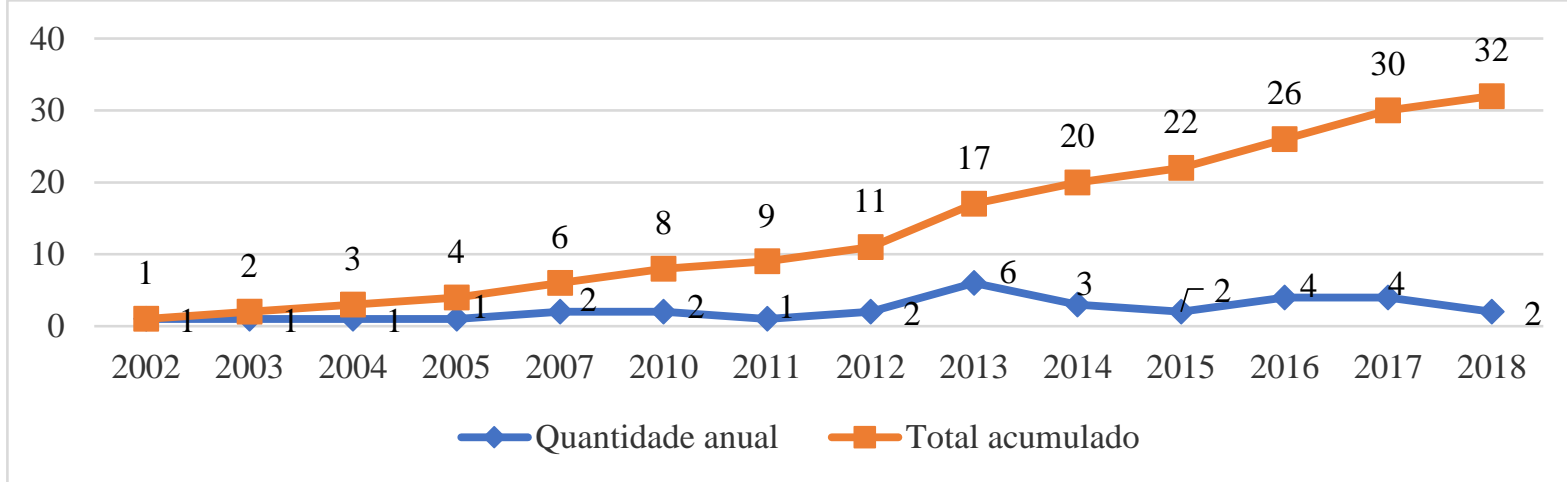

Fonte: Elaborada a partir de dados do INPI (2020) 
d) Das 32 patentes nacionais, somente 5 foram concedidas $(15,6 \%)$, as quais foram depositadas por pessoas jurídicas e estão concentradas nas regiões Sudeste e Sul, sendo 2 de Minas Gerais, 2 do Paraná e 1 de São Paulo.

e) 10 patentes de Remediação Ambiental (31\%) depositadas no INPI têm Universidades como depositantes/titulares. A grande maioria com propriedade ou titularidade de Universidade Federal, sendo que em uma delas foi identificada parceria, tendo a UNICAMP como depositante/titular e uma Universidade Federal como cotitular; apenas uma outra da UFMG está concedida, que é também a primeira patente nacional, a qual foi depositada em 2002 e cuja concessão se deu aproximadamente 11 anos depois, em 2013.

Entre as demais (69\%), há cotitularidade de Universidade Federal em 01 patente, especificamente, a Federal de Lavras, com depositante/titular a Fundação de Amparo à Pesquisa do Estado de Minas Gerais, a qual foi depositada em 2005 e concedida em 2016, aproximadamente 11 anos depois, assim como aquela com titularidade da UFMG.

f) Entre as patentes com titulares tipo empresa, destaca-se a empresa Geologia e Engenharia Ambiental LTDA (GEOAMBIENTE), como depositante/titular nacional, com atuação em soluções inovadoras para diagnóstico e remediação ambiental, com maior número de patentes de Remediação Ambiental no INPI (4), sendo 2 concedidas em 2020, aproximadamente 6 anos após depósito (2014): "Ponteira telescópica" (BR 2020140191114 ) e "Tecnologias de vácuo" (BR 202014019108 4). As outras 2 estão em fase de análise: "Misturas de persulfato de sódio e peróxido de cálcio" (BR 102015002135 6) e "Aplicação de carvão ativado" (BR 102016024428 5).

De acordo com os serviços descritos no portfólio da empresa (http://www.geoambiente.eng.br/, recuperado em junho, 2020), as 4 patentes mencionadas já vêm sendo utilizadas pela empresa. Supõe-se então, que estas tecnologias não tenham sido valoradas, uma vez que constituem serviços utilizados pela própria empresa, de modo que a patente foi requerida para impedir o uso por terceiros. Adicionalmente, não houve retorno acerca de solicitação de informações enviada por mensagem eletrônica.

g) Entre as patentes concedidas, ressalta-se a titularidade da Fundação de Amparo à Pesquisa do Estado de Minas Gerais (FAPEMIG) e cotitularidade da Universidade Federal de Lavras (UFLA), para a patente relativa à produção de carvão ativado a partir de grãos de café, visando sua aplicação em remediação ambiental (PI 0502449-8). Foi depositada em 2005 e concedida em 2016. A FAPEMIG (https://fapemig.br/pt, recuperado em julho, 2020) oferece vários serviços de PI em seu portfólio, tais como: proteção intelectual; transferência de tecnologia (TT); apoio a inventores independentes e apoio aos NITs. Em notícia divulgada no 
sítio oficial da Universidade (https://ufla.br/arquivo-de-noticias/9746-tecnologiadesenvolvida-na-ufla-para-a-producao-de-carvao-ativado-com-graos-de-cafe-recebe-cartapatente, recuperado em julho, 2020), é ressaltada a importância da carta-patente no processo de TT. Entretanto, por meio de contato eletrônico em 8 de julho de 2020, a referida tecnologia não foi oficialmente licenciada até aquela data.

h) $\mathrm{O}$ Instituto de Pesquisas Tecnológicas (IPT), vinculado à Secretaria de Desenvolvimento Econômico do Estado de São Paulo, também possui uma patente de Remediação Ambiental (BR 202012030497 5), com depósito em 2012 e concessão em 2019. O IPT (https://www.ipt.br/, recuperado em julho 2020) atua em inovação, pesquisa e desenvolvimento. Oferece catálogo com as patentes disponíveis para licenciamento, porém com última atualização em 2016 e não inclui a patente em questão. A partir de levantamento de dados, considerada a lei de transparência, foi realizado contato por e-mail em julho de 2020 , obtendo informação de que a tecnologia ainda não foi valorada.

i) A UFMG obteve a $1^{\text {a }}$ patente nacional de Remediação Ambiental concedida (2013), sendo também a $1^{\text {a }}$ nacional depositada com este tema. Apesar do sítio da Coordenadoria de Transferência e Inovação Tecnológica (CTIT-UFMG) (http://www.ctit.ufmg.br/vitrinetecnologica/, recuperado em julho, 2020), conter Vitrine Tecnológica com lista de patentes para TT, além de um documento com contratos de licenciamento já realizados, a patente em questão (PI 0200516-6) não foi localizada em ambos. Segundo CONTATO 2 (6, julho, 2020), por $e$ mail, obteve-se informação de que a referida patente foi abandonada segundo critérios definidos pela Instituição. A partir de novo contato com solicitação de informações, até 9 de julho de 2020, foram valorados 61 pedidos de patentes desde 2012, utilizando o método de valoração por custo, por mercado e por renda, sendo as de remediação ambiental por mercado e por renda, complementando que desenvolveu 3 diferentes métodos de valoração a partir de referências acadêmicas para atender suas demandas mais recorrentes.

Ainda relacionado ao INPI, a base de TTs contém apenas 01 registro, datado de 2009, referente a um projeto conceitual e acompanhamento da remediação de áreas impactadas devido acidentes ambientais, sendo um serviço de assistência técnica e científica da Hydrogeo Plus Inc. do Canadá para a Petrobras, no Brasil. O pagamento é por hora, variando entre CAD85,00 e CAD297,75 (dólares canadenses), com prazo de execução dos serviços entre 30/06/2012 e 30/06/2013, cujo equivalente em moeda brasileira (Real), à época (01/07/2012), estava entre $\mathrm{R} \$ 173,53$ e $\mathrm{R} \$ 607,86$, a partir do valor médio do dólar canadense (2,04 reais) naquele período, pelo sítio INVESTING.COM (https://br.investing.com/currencies/cad-brl-historical-data, 
recuperado em junho 2020). Ressalta-se que apesar de não constituir patente, foi acrescida à discussão por se tratar de informação complementar à temática em foco.

Com relação aos NITs que vêm valorando patentes e os métodos que foram empregados, devido ao pequeno número de artigos na literatura, com relatos de experiências a partir dos NITs, as respostas a partir dos questionários, embora totalizando apenas 10, permitiram complementar informações, devido detalhamento e confiabilidade.

O quantitativo de patentes depositadas pelos NITs participantes é bastante distinto (Tabela 1), lembrando que apenas dois estados (BA e MG) tiveram dois responsáveis por NITs, sendo que um deles atende 3 estados, simultaneamente (NIT01-BA/PE/PI-Tabela 1).

Tabela 1 - Quantitativo de patentes depositadas, licenciadas e valoradas por unidade de federação do Brasil

\begin{tabular}{lcccc}
\hline NITs & $\begin{array}{c}\text { Total } \\
\text { Depositadas }\end{array}$ & $\begin{array}{c}\text { Total } \\
\text { Licenciadas }\end{array}$ & $\begin{array}{c}\text { Total } \\
\text { Valoradas }\end{array}$ & Remediação Ambiental Valoradas (Quant.) \\
\hline NIT01 - BA/PE/PI & 55 & 0 & 5 & Não \\
NIT02 - AL & 7 & 0 & 1 & Não \\
NIT03 - MT & 31 & 0 & 4 & Sim (2) \\
NIT04 - MG & 144 & 5 & 30 & Não \\
NIT05 - MA & 154 & 2 & 0 & Não \\
NIT06 - SE & 193 & 2 & 8 & Não \\
NIT07 - MG & 138 & 1 & 2 & Não \\
NIT08 - BA & 10 & 0 & 0 & Não \\
NIT09 - PR & 105 & 5 & 0 & Não \\
NIT10 - SP & 70 & 4 & 10 & Sim* \\
\hline
\end{tabular}

*O respondente não informou a quantidade.

Fonte: Pesquisa de campo (2020).

O número de patentes licenciadas e/ou valoradas é muito baixo em comparação àquele de patentes depositadas (Tabela 1), correspondendo a apenas 2,09\% e 6,62\%, respectivamente. Por outro lado, apesar do pequeno número de respondentes, o baixo percentual de patentes licenciadas em comparação com o total de depósitos está de acordo com os resultados da pesquisa FORTEC de Inovação (Torkomian, Bezerra, \& Silva, 2019), visto que 43,4\% dos respondentes possuíam 685 acordos de licenciamento em 2018 e apenas 4,32\% do total de 15.860 pedidos de proteção até o final do mesmo ano.

O NIT de Minas Gerias possui o maior número de patentes valoradas (30) e o NIT de Sergipe tem o maior número de patentes depositadas (193). Análise da Tabela 1 aponta ainda que algumas tecnologias foram licenciadas sem uma devida valoração prévia (MA e PR), e que, a partir das metodologias de cálculo utilizadas pelos gestores de NITs (Quadro 1), duas foram desenvolvidas na própria ICT, visando atender as especificidades de suas tecnologias. 
Quadro 1 - Metodologias utilizadas na valoração de patentes

Método de Opções Reais e Método de Abordagem de Mercado.

Uma banca de especialistas de mercado, analisando a quantidade de horas usadas até o atual estágio do produto, levantando uma média de preços dos itens utilizados para desenvolver o produto acabado, uma estimativa de horas de trabalho para escala industrial. Quando a patente já foi desenvolvida em parceria com a empresa utilizamos as médias de custos industriais somadas as horas de estudos e pesquisas envolvidas.

Regra dos $25 \%$ e múltiplos de mercado.

Método de Pita; Possibilidade de Negociação e Regra dos $25 \%$.

Avaliação qualitativa e quantitativa de patentes. O modelo qualitativo consiste em critérios e subcritérios com pesos e foi desenvolvido a partir da adaptação de uma sessão do software IPscore ${ }^{\circledR}$ e da metodologia de Análise Hierárquica de Processos (AHP). O modelo quantitativo é baseado no fluxo de caixa descontado e na árvore de decisão com análise de cenários.

Somente referência a Portaria MF 436/58 (1958).

Custo do projeto, parâmetros operados pelo mercado.

Fonte: Pesquisa de campo (2020).

O IPscore foi utilizado para propor uma metodologia para a valoração de patentes e projetos de desenvolvimento tecnológico, com versão 2.2 (2009) desenvolvida pelo European Patent Office (EPO), baseada em versão da Dinamarca (https://www.epo.org/searching-forpatents/business/ipscore.html, recuperado em junho, 2020). A versão da EPO é gratuita, podendo ser utilizada no monitoramento das patentes, auxiliando suas aplicações ou abandono daquelas, potencialmente, sem valor. O manual cita que o software baseia-se em modelo matemático e não garante um valor real, com decisão tomada por conta e risco do usuário.

A maioria dos NITs, que valoram as patentes, utiliza o "Método de Pita; a Possibilidade de Negociação e a Regra dos 25\%”, sendo bastante utilizados no NIT de Minas Gerais, porém nenhuma com aplicação em processos de Remediação Ambiental.

Sobre as dificuldades ou desafios enfrentados para valoração das patentes, foram citados: 1) Ausência de softwares com este objetivo; 2) Ausência de métodos mais práticos e validados; 3) Falta de base mercadológica para analisar custos e preços de mercado; 4) Maturidade do pesquisador (inventor) em valorar; 5) Falta de pessoal especializado; 6) Falta de base de custo da pesquisa pelos inventores; 7) Ausência de informação em relação aos custos do invento; 8) Falta de metodologia e parâmetros para valoração de patentes de processo em especial; e 9) Incerteza e novidade dos mercados e das tecnologias.

Registra-se também o desafio para cálculo de 3 tipos de custos: custo da pesquisa/invento; custo associado ao histórico de custo de mercado para novas tecnologias; e o custo para seu processamento e/ou sua aceitação no mercado devido caráter de novidade. Além disso, alguns participantes reforçam a falta de pessoal e de especialistas nos NITs e comentário adicional destaca a relevância do tema e a importância de treinamentos e cursos.

Os dados relativos às patentes de Remediação Ambiental que foram valoradas, por parte de alguns respondentes, são limitadas ao nome do método, sem detalhamento ou resultados do 
processo. Ademais, em concordância com Hung e Tseng (2010), ratifica-se o papel de indicadores com pesos adicionais para ganhos ambientais e sociais. De acordo com as respostas, 2 patentes com foco na remediação ambiental de um NIT do Mato Grosso foram valoradas por "Regra dos 25\% e múltiplos de mercado" e pelo menos uma de um NIT de São Paulo por "Custo do projeto, parâmetros operados pelo mercado". No primeiro caso, as duas patentes não foram licenciadas e no segundo, não foi possível concluir, pela falta de detalhamento entre o que foi valorado e o que foi licenciado.

Complementando a discussão, deve-se atentar que 50\% dos respondentes dos NITs participantes da Pesquisa FORTEC de Inovação-ano base 2018 (Torkomian et al., 2019) terceirizam pelo menos 1 atividade do NIT, com 10,7\% relacionadas à terceirização dos processos de valoração, ou seja, uma das alternativas para que os NITs obtenham valoração prévia à negociação.

\section{Conclusão}

Diante dos impactos ambientais, as ICTs e empresas vêm investindo em inovações com foco no meio ambiente, com a China liderando quanto à proteção de tecnologias na área de remediação ambiental. No Brasil, o número de patentes na área é muito pequeno. Nas bases de dados do Orbit e do INPI, há apenas 43 e 45 patentes de remediação ambiental com primeira prioridade no Brasil, respectivamente, as quais foram depositadas entre 2002 e maio de 2020, sendo 31 (Orbit) e 32 (INPI) com depositantes residentes, com destaque para o estado de São Paulo. Ademais, poucas patentes concedidas na área estão concedidas (15,6\%).

Quanto à valoração, nota-se que os métodos disponíveis não vêm suprindo satisfatoriamente. Em geral, faltando validações e/ou detalhamentos para sua compreensão e utilização em casos reais. Para tecnologias ligadas à Remediação Ambiental, as especificidades da área não vêm sendo consideradas, tal como pesos adicionais a partir da verificação de redução de impactos ambientais, por exemplo.

Aponta-se a valoração como gargalo para TT, devido escassez de métodos e softwares precisos e confiáveis. Ademais, os dados da pesquisa com gestores de NITs ratificaram e complementaram informações, com pequeno número de patentes valoradas e/ou licenciadas em comparação com aquelas depositadas, além da ocorrência de licenciamentos de tecnologias sem a devida valoração prévia.

Destarte, os métodos para valoração de patentes, informados pelos respondentes, devem ser analisados previamente quando em busca de um novo método ou adaptação. A maioria das 
patentes foi valorada pelo "Método de Pita; Possibilidade de Negociação e Regra dos 25\%". Quanto à Remediação Ambiental, destaca-se um NIT do Mato Grosso, com valoração de 2 patentes, utilizando a "Regra dos $25 \%$ e múltiplos de mercado", e um NIT de São Paulo, com uma valoração de patente na área pelo método de "Custo do projeto, com parâmetros operados pelo mercado". Em nenhum dos casos foram relatados critérios relativos aos ganhos advindos do cumprimento de responsabilidades sociais e competitividade.

Isto posto, a valoração de patentes, incluindo aquelas na área de Remediação Ambiental, enfrenta desafios que podem ser superados pela disponibilidade de softwares e/ou de métodos mais completos e validados, pessoal especializado, capacitações, detalhamentos dos custos envolvidos, critérios adicionais relativos às áreas estratégicas, como a ambiental, além de parâmetros para estimar as incertezas dos mercados e desenvolvimento das pesquisas.

\section{Referências}

Adriano, E., \& Antunes, M. T. P. (2017). Proposta para Mensuração de Patentes. Revista de Administração Contemporânea, 21 (1).

Aguiar, R. M., Gabriel, M. L. D. S. (2014). Remediação de Áreas Contaminadas Por Cromo Hexavalente: Relato Sobre Gerenciamento De Projeto. Revista Inovação, Projetos $e$ Tecnologias - IPTEC, 2 (1), 67-84.

Amaral, H., Iquiapaza, R. A., Correia, L. F., Amaral, G. H. O., \& Vieira, M. V. (2014). Avaliação de Ativos Intangíveis: Modelos Alternativos para Determinação do Valor de Patentes. Revista de Gestão, Finanças e Contabilidade, UNEB, Salvador, 4 (1), 123-143.

Andriessen, D. (2004). Making sense of intellectual capital: design a method for the valuation of intangibles. Oxford, USA: Elsevier Butterword-Heinemann.

Banerjee, A., Bakshi, R., \& Sanyal, M. K. (2017). Valuation of patent: A classification of methodologies. Research Bulletin, 42 (4), 158-174.

Damodaran, A. (2006). Dealing with Intangibles: valuing brand names, flexibility and patents. New York: Stern School of Business.

Ernst, H., Legler, S., \& Lichtenthaler, U. (2010). Determinants of patent value: Insights from a simulation analysis. Technological Forecasting \& Social Change, 77, 1-19.

Gil, A. C. (2017). Como Elaborar um Projeto de Pesquisa. 6. ed. São Paulo: Atlas.

Hitchner, J. R., \& Mard, M. J. (2006). Financial valuation workbook, 2nd Ed., John Wiley \& Sons, Inc.

Hong, S. J., Seo, J. W., Kim, Y. S., \& Kang, S. H. (2010). Construction Technology Valuation for Patent Transaction. KSCE Journal of Civil Engineering. 
Hung, S. W., \& Tseng, S. C. (2010) A New Framework Integrating Environmental Effects into Technology Evaluation. Journal of Business Ethics, 95, 543-556.

Oliveira, J. A., \& Ewald, M. R. (2012). Sistemas de gestão ambiental como auxílio para processos industriais limpos. In: SILVEIRA, M. A. Gestão da Sustentabilidade Organizacional: Inovação, Aprendizagem e Capital Humano. Campinas, SP: CTI (Centro de Tecnologia da Informação "Renato Archer").

Portaria MF 436/58, de 30 de dezembro de 1958 (1958). Portaria do Ministério da Fazenda que estabeleceu coeficientes percentuais máximos para a dedução de Royalties pela exploração de patentes, entre outros.

Quintal, R. S., \& Terra, B. R. C. S. S. R. (2014). Políticas organizacionais de ciência, tecnologia e inovação e gestão da propriedade industrial: uma análise comparativa em Instituições de Pesquisa. Gestão \& Produção, São Carlos, 21 (4), 760-780.

Reitzig, M. (2003). What determines patent value? Insights from the semiconductor industry, Research Policy, 32 (1), 13-26.

Resolução INPI no 239/2019, de 4 de junho de 2019 (2019). Disciplina o trâmite prioritário de processos de patente no âmbito da Diretoria de Patentes, Programas de Computador e Topografias de Circuitos Integrados (DIRPA).

Romeiro, A. R., \& Salles, S. (2011). Dinâmica de inovações sob restrição ambiental. In A. R. Romeiro, B. P. Reydon, \& M. L. A. Leonardi. Economia do meio ambiente: teoria, políticas e a gestão de espaços regionais. Campinas, SP: UNICAMP, Instituto de Economia.

Romer, P. (1987). Growth based on increasing returns due to specialization. American Economic Review, 77.

Sapsalis, E., \& Van Pottelsberghe De La Potterie, B. (2007). The institutional sources of knowledge and the value of academic patents, Econ. Innov. New technol. 16.

Souza, R. de O. (2009). Dissertação (Mestrado). Valoração de ativos intangíveis: seu papel na transferência de tecnologias e na promoção da inovação tecnológica. Rio de Janeiro: Universidade Federal do Rio de Janeiro. Disponível: http://tpqb.eq.ufrj.br/download/valoracao-de-ativos-intangiveis.pdf

Thorn, H., Hunt, F., Mitchell, R., Probert, D., \& Phaal, R. (2011). Internal technology valuation: real world issues. International Journal of Technology Management (IJTM), 53 (2/3/4).

Torkomian, A. L. V., Bezerra, S. Y. A. F, \& Silva, K. C. (2019). Relatório anual da Pesquisa FORTEC de Inovação - Ano Base 2018. 